\title{
Article \\ Transcriptome Analysis Revealed a Positive Role of Ethephon on Chlorophyll Metabolism of Zoysia japonica under Cold Stress
}

\author{
Jiahang Zhang ${ }^{1}{ }^{\oplus}$, Zhiwei Zhang ${ }^{1,2}$, Wen Liu ${ }^{1}$, Lijing Li ${ }^{1}$, Liebao Han ${ }^{1}$, Lixin $\mathrm{Xu}^{1, *}{ }^{1}$ and Yuhong Zhao ${ }^{3, *}$ \\ 1 College of Grassland Science, Beijing Forestry University, Beijing 100083, China; 15104490515@163.com (J.Z.); \\ zhangzw559@163.com (Z.Z.); bxliuwen@163.com (W.L.); 1lj15122428388@163.com (L.L.); \\ hanliebao@163.com (L.H.) \\ 2 CCTEG Ecological Environment Technology Co., Ltd., Beijing 100013, China \\ 3 Animal Science College, Tibet Agriculture \& Animal Husbandry University, Nyingchi 860000, China \\ * Correspondence: lixinxu@bjfu.edu.cn (L.X.); yuhong19801011@126.com (Y.Z.)
}

check for updates

Citation: Zhang, J.; Zhang, Z.; Liu, W.; Li, L.; Han, L.; Xu, L.; Zhao, Y. Transcriptome Analysis Revealed a Positive Role of Ethephon on Chlorophyll Metabolism of Zoysia japonica under Cold Stress. Plants 2022, 11, 442. https://doi.org/ $10.3390 /$ plants 11030442

Academic Editors: Hye Ryun Woo and Georgia Ouzounidou

Received: 31 December 2021

Accepted: 3 February 2022

Published: 5 February 2022

Publisher's Note: MDPI stays neutral with regard to jurisdictional claims in published maps and institutional affiliations.

Copyright: (c) 2022 by the authors. Licensee MDPI, Basel, Switzerland. This article is an open access article distributed under the terms and conditions of the Creative Commons Attribution (CC BY) license (https:// creativecommons.org/licenses/by/ $4.0 /)$.

\begin{abstract}
Zoysia japonica is a warm-season turfgrass with a good tolerance and minimal maintenance requirements. However, its use in Northern China is limited due to massive chlorophyll loss in early fall, which is the main factor affecting its distribution and utilization. Although ethephon treatment at specific concentrations has reportedly improved stress tolerance and extended the green period in turfgrass, the potential mechanisms underlying this effect are not clear. In this study, we evaluated and analyzed chlorophyll changes in the physiology and transcriptome of Z. japonica plants in response to cold stress $\left(4^{\circ} \mathrm{C}\right)$ with and without ethephon pretreatment. Based on the transcriptome and chlorophyll content analysis, ethephon pretreatment increased the leaf chlorophyll content under cold stress by affecting two processes: the stimulation of chlorophyll synthesis by upregulating $\mathrm{ZjMgCH} 2$ and $\mathrm{ZjMgCH} 3$ expression; and the suppression of chlorophyll degradation by downregulating ZjPAO, ZjRCCR, and ZjSGR expression. Furthermore, ethephon pretreatment increased the ratio of chlorophyll a to chlorophyll $b$ in the leaves under cold stress, most likely by suppressing the conversion of chlorophyll a to chlorophyll $b$ due to decreased chlorophyll $b$ synthesis via downregulation of $\mathrm{ZjCAO}$. Additionally, the inhibition of chlorophyll b synthesis may result in energy redistribution between photosystem II and photosystem I.
\end{abstract}

Keywords: chlorophyll content; cold stress; ethephon; transcriptome; Zoysia japonica

\section{Introduction}

Zoysia japonica (Z. japonica) is a warm-season turfgrass species with good traffic stress tolerance and minimal maintenance requirements. It is widely used in China for sports turf, landscaping, and soil and water conservation [1,2]. However, in Northern China, the use of Z. japonica is relatively limited due to its short green period [3]. Temperature is the main factor affecting its natural distribution, turf quality, and popularization [4].

Low-temperature stress affects photosynthesis [5], the cell membrane [6,7], antioxidant systems [8], and other physiological and biochemical processes in plants [9]. Lowtemperature conditions especially alter photosynthesis functions [10], among which light energy absorption, gas exchange, and carbon assimilation are the most low-temperature susceptible processes [11]. Chlorophyll (Chl) fluorescence is reduced in Zoysia japonica (zoysiagrass) under natural chilling stress, suggesting that photosystem (PS) II is impaired by photoinhibition $[12,13]$. Short-term cold stress ( 2 and $72 \mathrm{~h}$ cold treatment at $4{ }^{\circ} \mathrm{C}$ ) can also induce oxidative stress and inhibit photosynthesis in Z. japonica [14]. However, the effect that a pretreatment with ethephon, a commercially available plant growth regulator, has on Z. japonica under long-term cold stress is still unclear.

Cold stress affects both the synthesis and degradation of Chl $[15,16]$. The decreased $\mathrm{Chl}$ content under low-temperature stress may be due to the inhibition of Chl biosynthesis 
and/or the acceleration of $\mathrm{Chl}$ degradation [17]. In rice, the Chl synthesis decrease under low-temperature conditions is triggered by the inhibition of $\delta$-aminolevulinic acid (ALA) synthesis and the suppression of the protochlorophyllide (Pchlide) conversion into Chl due to the downregulation of the protochlorophyllide oxidoreductase (POR) gene [18]. A transcriptome study in Z. japonica revealed that $72 \mathrm{~h}$ of cold stress treatment was associated with the downregulation of several differentially expressed genes (DEGs) involved in Chl synthesis and the upregulation of DEGs involved in Chl degradation. Specifically, two genes were upregulated: the gene encoding ferrochelatase $(\mathrm{Hem} \mathrm{H})$, which catalyzes the insertion of ferrous iron into protoporphyrin IX to form protoheme that departs from the Chl biosynthetic pathway, and the gene encoding pheophorbide $a$ oxygenase (PAO), which catalyzes the porphyrin macrocycle cleavage of pheophorbide a to generate a primary fluorescent Chl catabolite [14,19].

Ethylene acts as a plant hormone actively involved in plant stress response [20-22]. However, as a gaseous agent, the direct application of ethylene in production practice is difficult [23]. The disadvantages associated with its application can be overcome with ethephon, an ethylene-releasing reagent with great potential in outdoor use [23,24]. Interestingly, using a certain concentration of ethephon can improve the cold resistance of grape (Cabernet Sauvignon) [25], larch (Larix gmelinii) [26], and banana seedlings $($ Musa $\times$ paradisiaca $)$ [27]. At a specific concentration, ethephon can help to maintain a high $\mathrm{Chl}$ content in a submergence-tolerant rice (Oryza sativa L.) cultivar during submergence [28]. An ethephon pretreatment at a concentration of $150 \mathrm{mg} \mathrm{L}^{-1}$ can alleviate stress-related injuries in Z. japonica and reduce the loss of $\mathrm{Chl}$ under low-temperature conditions $[29,30]$. However, the mechanism underlying the effect of ethephon pretreatment has not been investigated and analyzed.

RNA sequencing (RNA-Seq) is a next-generation sequencing application with some clear advantages over existing sequencing methods [31,32]. Transcriptome analysis has also been applied to turfgrass species, including the bermudagrass [33], Kentucky bluegrass [34], creeping bentgrass [35], and Z. japonica [14]. A transcriptome analysis performed by Wang et al. [36] revealed that the gene families encoding auxin signal transduction proteins, ABA signal transduction proteins, and WRKY and bHLH transcription factors might represent the most critical components for salt-stress regulation in Z. japonica. Gene expression changes on the whole transcriptome level associated with ethephon pretreatment under cold stress have been rarely studied in Z. japonica.

The objective of this study was to explore the mechanism underlying the effect of ethephon on cold tolerance in Z. japonica and to prolong the green period of Zoysia japonica under cold stress. We assessed this effect by identifying the genes responding to ethephon treatment and analyzing the ethephon-induced key regulatory genes affecting the Chl metabolism in Z. japonica under cold stress.

\section{Results}

\subsection{Chlorophyll Content in Leaves}

The Chl analysis showed that CE plants had a significantly higher Chl content than CS plants $(p<0.05)$ (Figure 1A), demonstrating that ethephon pretreatment increased the $\mathrm{Chl}$ content under cold stress. Figure 1B shows that the ratio of Chla to Chlb did not change significantly, except for a slight increase in CE plants than in CS plants $(p=0.147)$ (Figure 1B). Moreover, the Chla/Chlb ratio change percentage relative to day 0 of $\mathrm{CE}$ plants was significantly lower than that of CS plants ( $\operatorname{sig}=0.027,0.001<0.05)$ (Figure $1 \mathrm{C})$, which indicated that ethephon pretreatment suppressed the decline of the Chla/Chlb ratio under cold-stressed conditions. Combined with the data in Figure 1B, it is affirmed that ethephon pretreatment could increase the Chla/Chlb ratio under cold stress. 


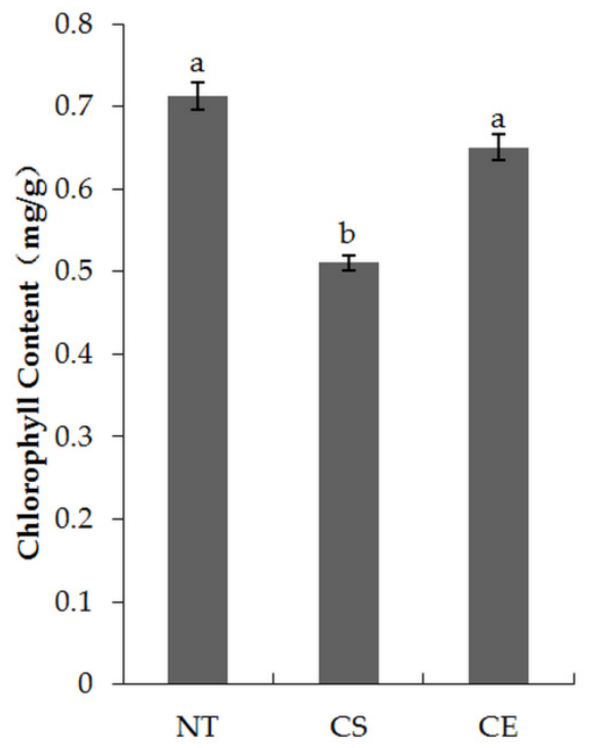

$(A)$

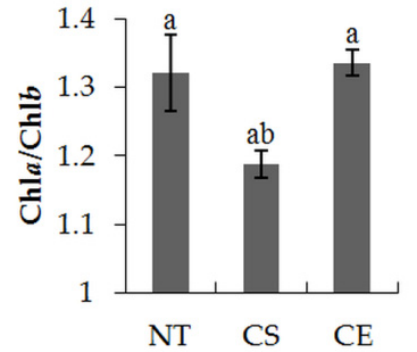

(B)

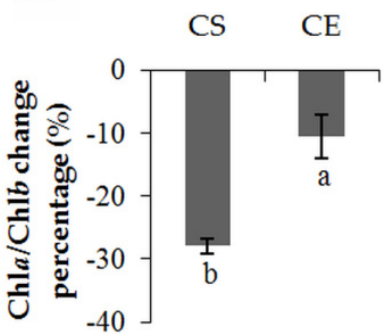

(C)

Figure 1. (A) Chlorophyll content in Z. japonica leaves; (B) Ratio of Chla to Chlb in Z. japonica leaves; (C) Chla/Chlb change percentage on day 28 relative to day 0 . Error bars represent standard deviations of three independent samples. Different letters indicate significant differences at $p<0.05$.

\subsection{Sequence Assembly}

A total of $75 \mathrm{Gbp}$ of clean sequencing data were obtained by a transcriptome analysis of all combined samples; the smallest clean data set had $6.7 \mathrm{Gbp}$ of sequencing data and the largest had $9.86 \mathrm{Gbp}$. After removing low-quality reads, an average of 55, 554, and 958 high-quality clean reads per sample was obtained, accounting for $97.57 \%$ of the sample's average raw reads. The percentage of Q30 bases reached over $90.51 \%$, and the GC content of the samples varied between $49.73 \%$ and $53.48 \%$. The clean reads of each sample were aligned with the reference genome of Z. japonica, reaching $93.06 \%$ of aligned reads for the sample with the highest efficiency and $88.08 \%$ of aligned reads for the sample with the lowest efficiency (Table 1). Thus, the sequencing data cleaning process generated a data set of high-quality reads that were mapped to the reference genome with a high efficiency and met the analysis requirements of subsequent tests.

Table 1. An overview of the RNA-Seq data.

\begin{tabular}{cccccccc}
\hline Sample & Raw Reads & Total Reads & Clean Reads & $\begin{array}{c}\text { Clean Bases } \\
\text { (Gbp) }\end{array}$ & $\begin{array}{c}\text { Q30 } \\
(\mathbf{\%})\end{array}$ & $\begin{array}{c}\text { GC Content } \\
\text { (\%) }\end{array}$ & $\begin{array}{c}\text { Total Map } \\
\text { (\%) }\end{array}$ \\
\hline CE1 ${ }^{1}$ & 51696468 & 50530932 & 50530932 & 7.58 & 90.95 & 51.3 & 91.45 \\
CE2 & 67066970 & 65714084 & 65714084 & 9.86 & 92.08 & 51.23 & 92.35 \\
CE3 & 65392538 & 64083968 & 64083968 & 9.61 & 92.1 & 52.98 & 93.06 \\
CS1 & 61806546 & 60439330 & 60439330 & 9.07 & 90.91 & 53.48 & 92.11 \\
CS2 & 59147316 & 58002528 & 58002528 & 8.7 & 90.51 & 53.46 & 92.19 \\
CS3 & 61224860 & 60038194 & 60038194 & 9.01 & 91.67 & 52.75 & 92.79 \\
NT1 & 50204448 & 48478352 & 48478352 & 7.27 & 92.51 & 49.73 & 88.08 \\
NT2 & 46169382 & 44677484 & 44677484 & 6.7 & 92.1 & 50.06 & 88.44 \\
NT3 & 49753502 & 48029758 & 48029758 & 7.2 & 92.21 & 49.75 & 87.66 \\
\hline
\end{tabular}

${ }^{1} \mathrm{CE}$, cold stress $\left(4^{\circ} \mathrm{C}\right)$ with ethephon spray pretreatment. ${ }^{2} \mathrm{CS}$, cold stress $\left(4^{\circ} \mathrm{C}\right)$ with water spray pretreatment

${ }^{3} \mathrm{NT}$, normal day/night temperature regimen $\left(28 / 18^{\circ} \mathrm{C}\right)$ with water spray pretreatment as control.

\subsection{Global Gene Expression Analysis}

The comparison of CS plants with NT plants (CS vs. NT) identified a total of 16,359 DEGs in the leaves, among which 9199 were upregulated, and 7160 were downregulated (Figure 2a). Gene ontology (GO) and an enrichment analysis identified 516 biolog- 
ical processes, 337 molecular functions, and 128 cellular components (Table S1). Among 16,359 cold-stress-related DEGs identified by the CS vs. NT comparison, there were 1618 DEGs with annotations in 113 KEGG pathways; 924 of those DEGs were upregulated, and 694 were downregulated (Table S2).

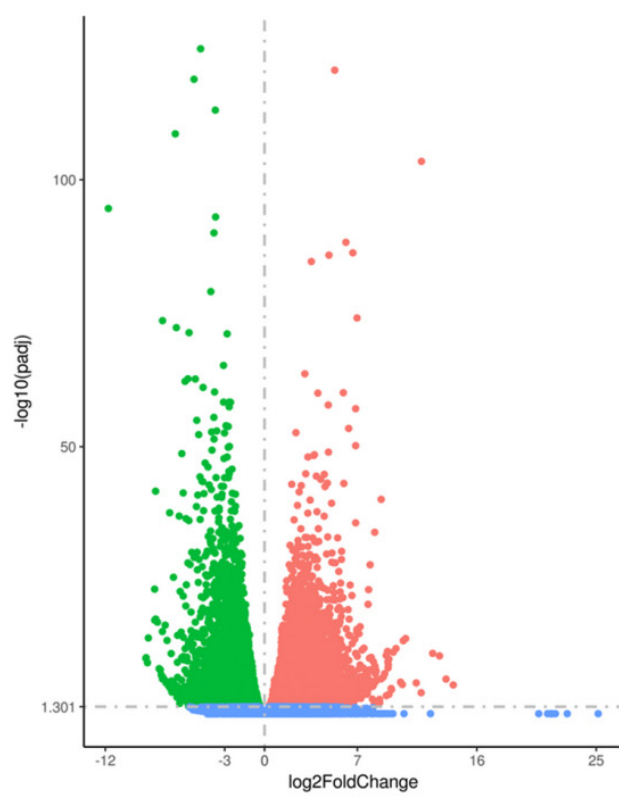

(a)

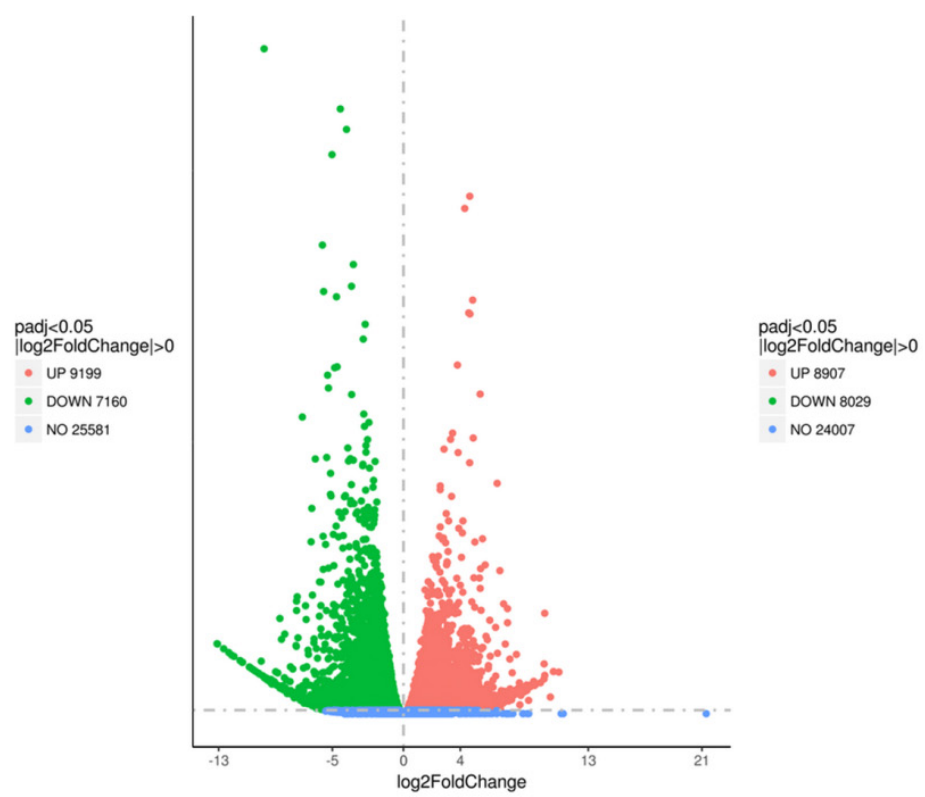

(b)

Figure 2. (a) Distribution of differential genes in volcanic map (CS vs. NT); (b) Distribution of differential genes in volcanic map (CEvs. NT).

The most DEGs in the leaves were identified by comparing CE plants with NT plants (CE vs. NT), with a total of 16,936 DEGs, among which 8907 were upregulated, and 8029 were downregulated (Figure 2b). GO and enrichment analysis identified 519 biological processes, 337 molecular functions, and 128 cellular components (Table S3). Among 16,359 DEGs, 1777 were annotated in 112 KEGG pathways, which included 931 upregulated and 846 downregulated DEGs (Table S4).

The heat map showed the overall effect of ethephon treatment under cold stress on transcription, and visualized how ethephon regulated the effect of cold stress on transcriptome (Figure S1). These results indicated that ethephon induced changes in the gene expression of $Z$. japonica under cold stress. Therefore, only the genes most relevant to ethephon application under cold stress are focused on in the study.

\section{4. qRT-PCR Confirmation}

These genes displayed a single dissociation peak and linearity between target cDNA and $\mathrm{Ct}$ values (Figure 3), showing that the genes used for qRT-PCR were consistent with the RNA-Seq results (Pearson's $r=0.94, p<0.001$ ).

\subsection{Differential Gene Expression Related to Photosynthesis-Antenna Proteins and Porphyrin and Chlorophyll Metabolism}

In the CE vs. NT comparison, the most-enriched KEGG pathways related to chlorophyll included "porphyrin and Chl metabolism" (Figure 4). The results indicated that ethephon can regulate chlorophyll metabolism to improve cold tolerance. Meanwhile, in land plants, the only depots of Chlb are antenna complexes, which are composed of light harvesting complex (Lhc) proteins, [37] and Chlb content can regulate light-harvesting complexes levels in plants (Ayumi, 2019). Therefore, we analyzed the DEGs, which were derived by matching the DEGs from CE vs. NT with those from CS vs. NT ((CE vs. NT) vs. 
(CS vs. NT)), annotated in KEGG pathways of porphyrin and Chl metabolism (osa00860) (Table S5) and photosynthesis-antenna proteins (osa00196) (Table S6).

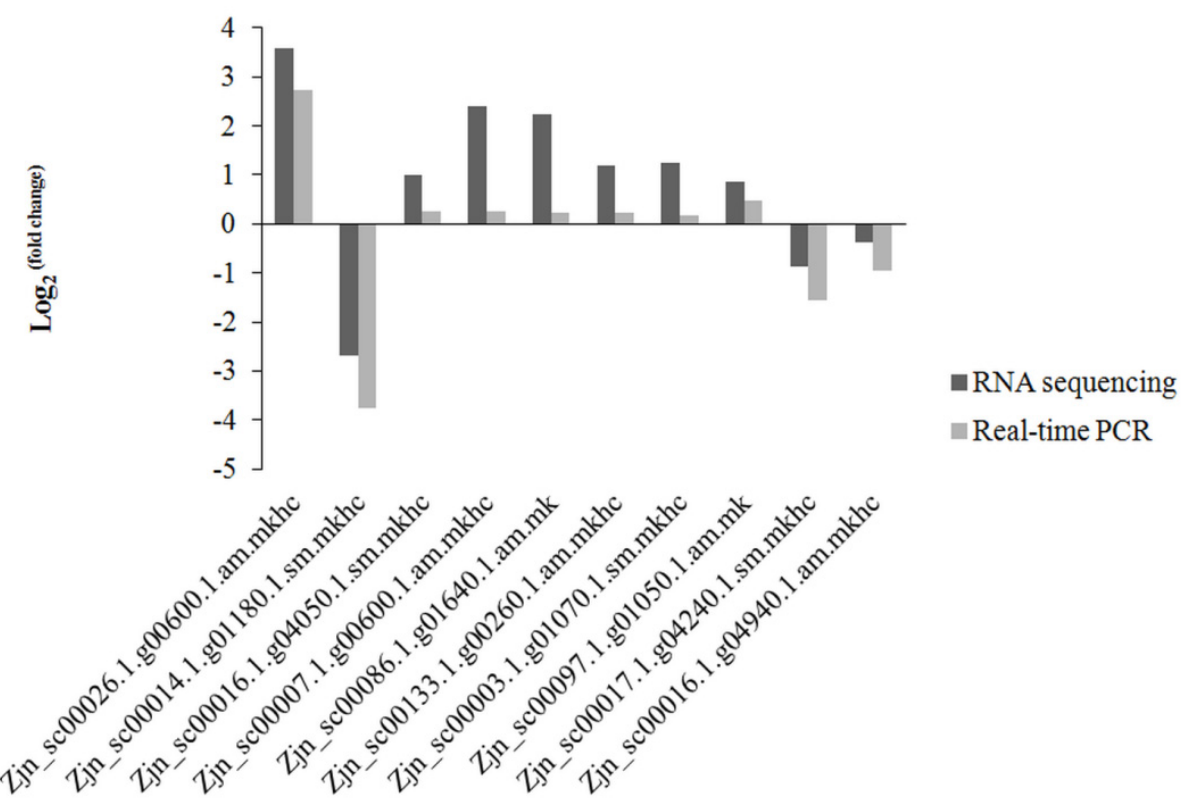

Figure 3. $\log _{2}$ (fold change) of genes based on RNA-Seq and qRT-PCR methods.

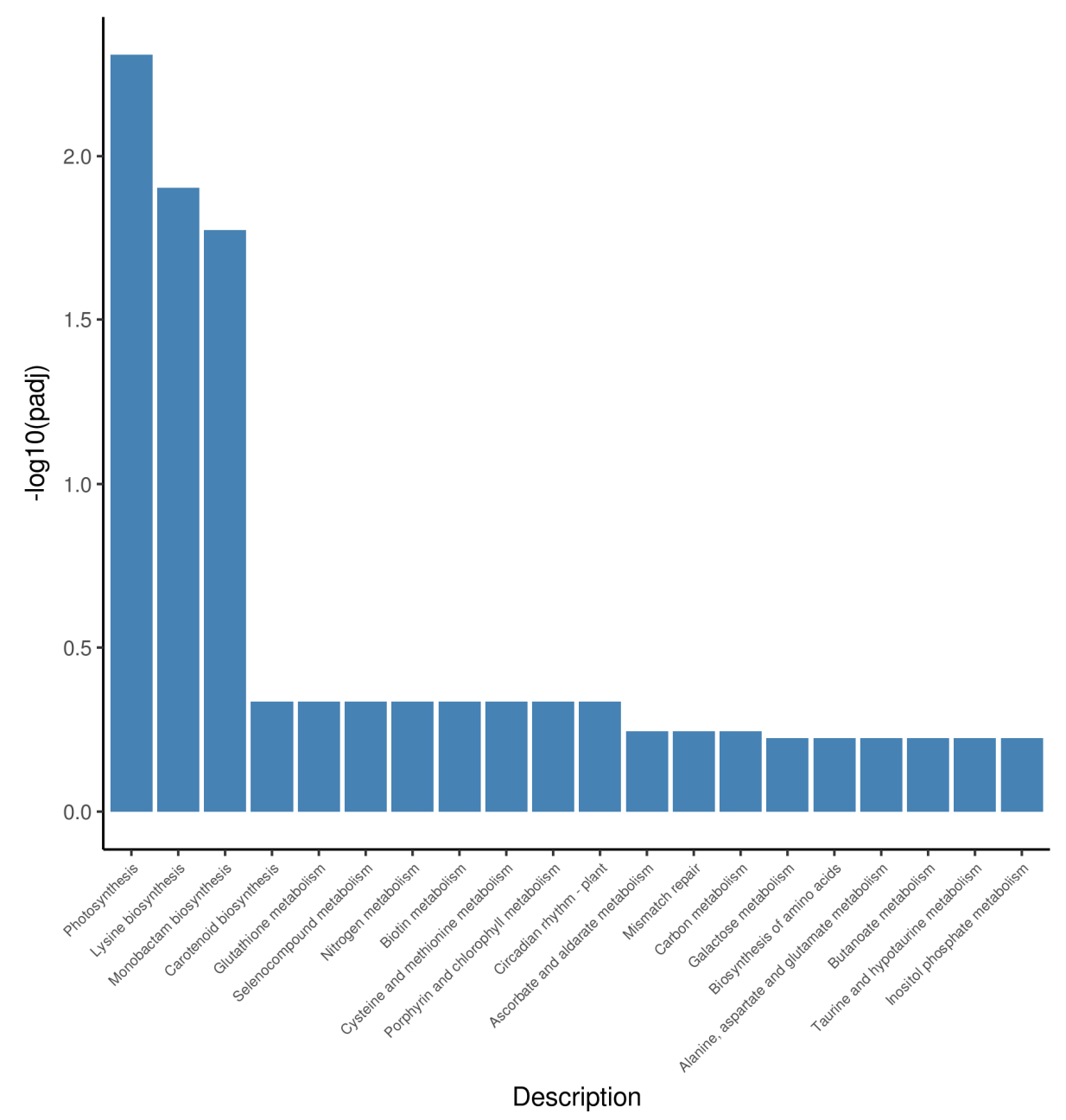

Figure 4. Enriched KEGG terms of CE vs. NT. 
The comparison of CS vs. NT identified seventeen DEGs in the porphyrin and Chl metabolism (Figure 5c). Under cold stress, ZjUroD1, ZjUroD2, ZjChlP1, ZjChlP2, ZjNYC1, ZjNADPH1, ZjPAO, ZjGSA, ZjPBGD, ZjGUS1, ZjHemA, ZjCLH, ZjSGR, ZjNADHB, and putative ZjCOX10 were upregulated, whereas ZjHY2 and ZjCPX were downregulated (Figure 5a). Twenty-four DEGs were identified by the comparison of CE vs. NT (Figure 5c). Ethephon pretreatment under cold stress was associated with the upregulation of ZjUroD1, ZjUroD2, ZjChlP1, ZjChlP2, ZjMgCH2, ZjMgCH3, ZjNYC1, ZjNADPH1, ZjGSA, ZjPBGD, ZjGUS1, ZjHemA, ZjNADHB, and putative ZjCOX10, and the downregulation of ZjNADPG2, ZjPAO, ZjCAO, ZjHY2, ZjCPX, ZjHMOX1, ZjMPE cyclase, ZjRCCR, ZjTPM, and ZjSGR (Figure 5a). There were sixteen DEGs found both in CS vs. NT and CE vs. NT (Figure 5c).

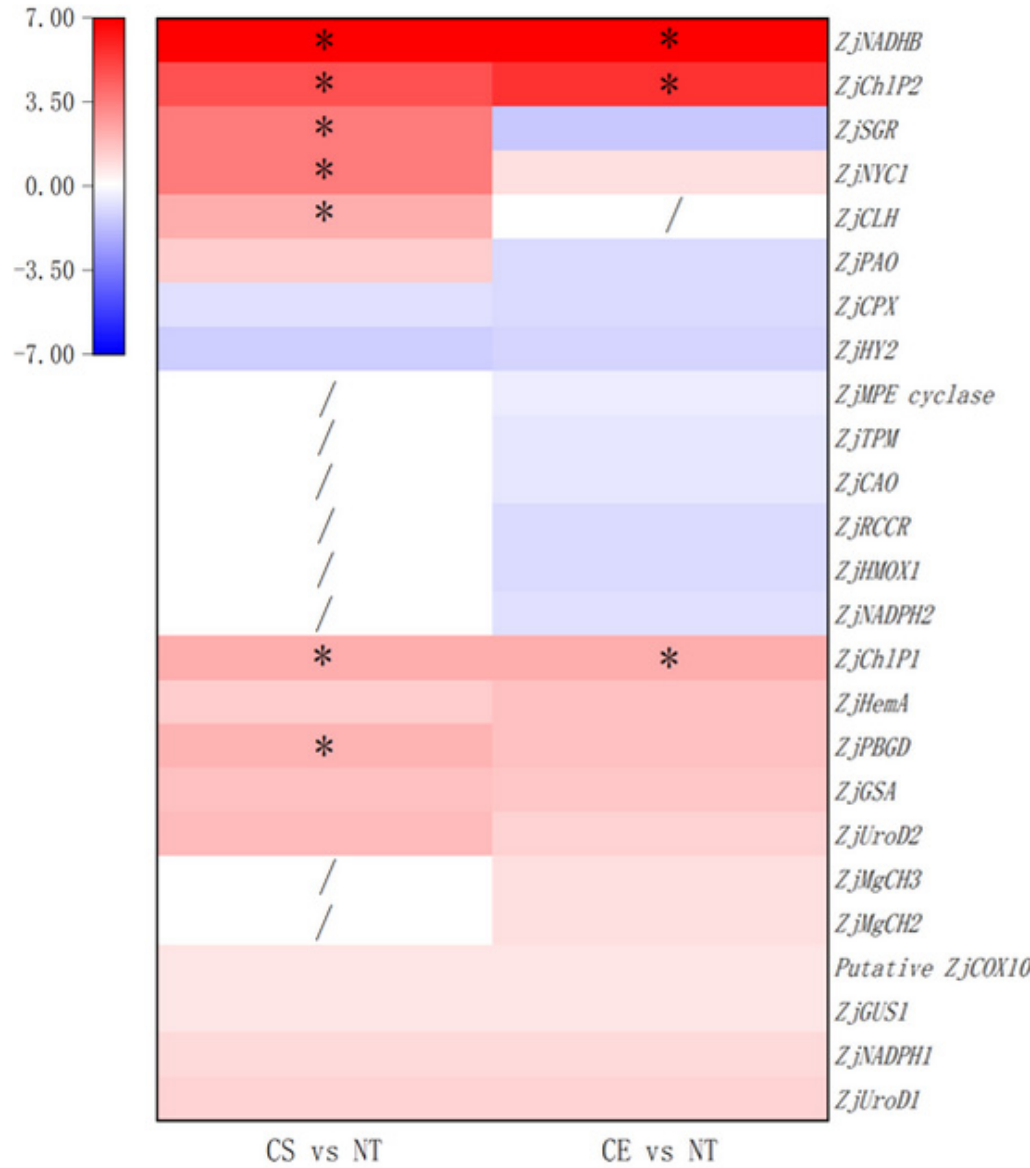

(a)

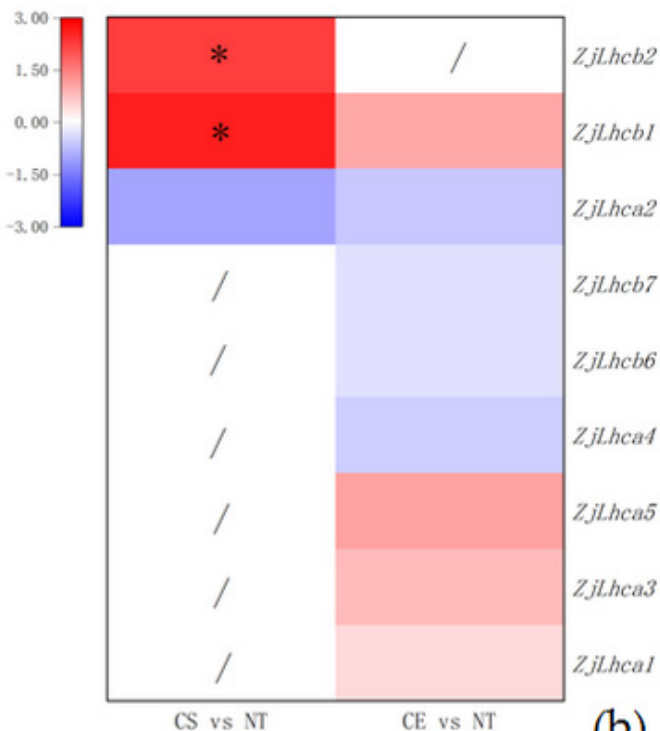

(b)

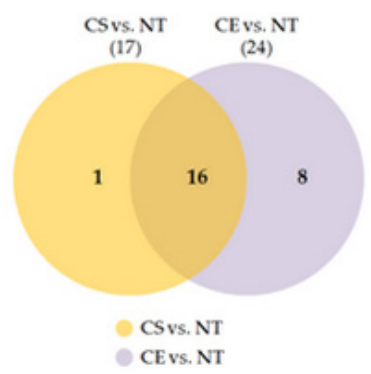

(c)

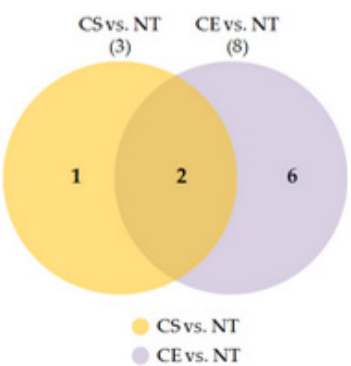

(d)

Figure 5. (a) Heat map of differentially expressed genes in porphyrin and chlorophyll metabolism pathway; (b) Heat map of differentially expressed genes in photosynthesis-antenna proteins pathway; (c) Venn diagram for all DEGs in porphyrin and chlorophyll metabolism pathway; (d) Venn diagram for all DEGs in photosynthesis-antenna proteins pathway; "/" indicates the DEG was not enriched in this KEGG pathway comparison; and "* " means the $\log _{2}$ (fold change) of this gene is greater than 2 . Gene expression in $\log _{2}$ (fold change) scale was elevated with red and decreased with blue.

Based on the CS vs. NT comparison, we identified three DEGs in the photosynthesisantenna protein pathway (Figure 5d). Under cold stress, ZjLhcb1 and ZjLhcb2 were upregulated, and ZjLhca2 was downregulated (Figure 5b). Eight DEGs were identified by the comparison of CE vs. NT (Figure 5d): ZjLhca1, ZjLhca3, ZjLhca5, ZjLhcb1 were upregulated, and ZjLhca2, ZjLhca4, ZjLhcb6, ZjLhcb7 were downregulated by ethephon pretreatment under cold stress (Figure 5b). There were two DEGs found in both CS vs. NT and CE vs. NT (Figure 5d). 


\section{Discussion}

\subsection{Gene Expression Analysis of Porphyrin and Chl Metabolism}

The Chl content is an important physiological index of plant tolerance to cold stress [38,39]. However, the effects of cold stress on $\mathrm{Chl}$ metabolism are modified by ethephon treatment. We found that ethephon pretreatment elevated the $\mathrm{Chl}$ content by regulating genes involved in $\mathrm{Chl}$ synthesis, the PAO-dependent Chl degradation pathway, and the Chl cycle (Figure 6a,b).

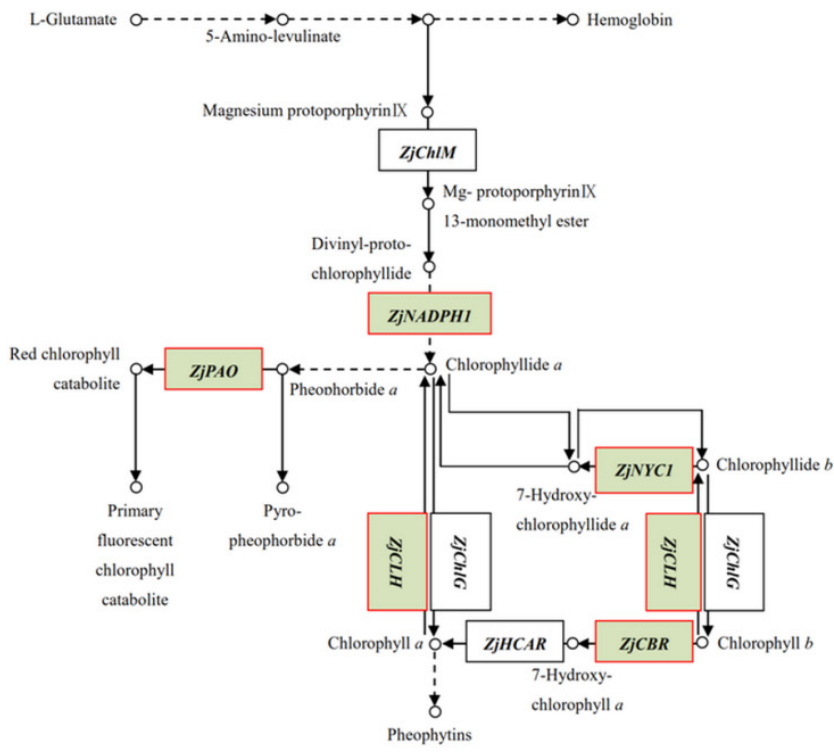

(a)

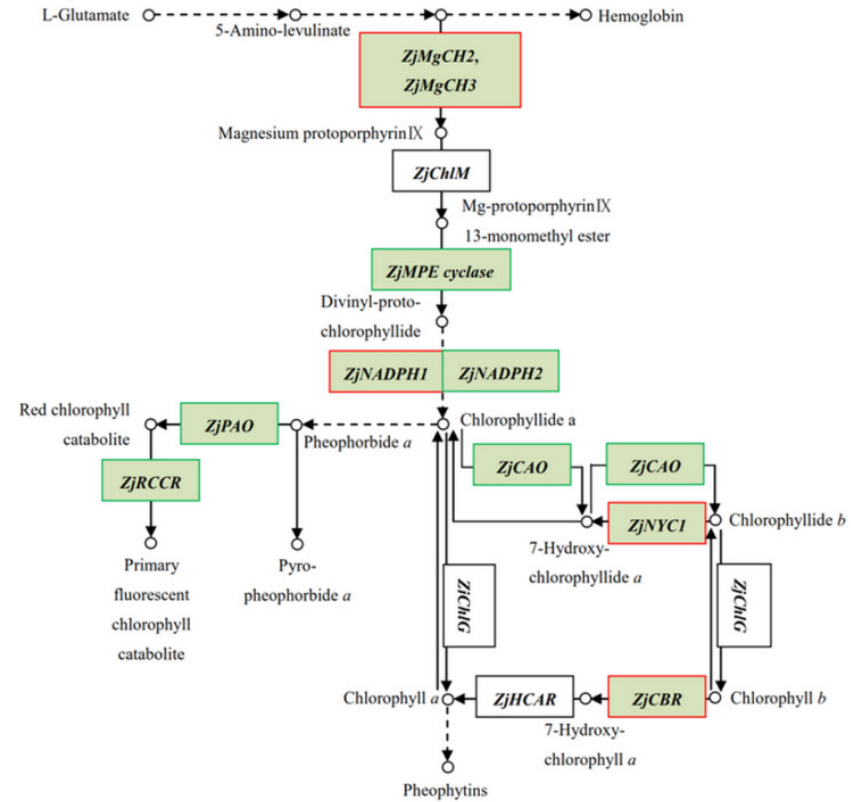

(b)

Figure 6. (a) KEGG metabolic pathway based on the comparison of CS vs. NT that matches the chlorophyll metabolic pathway; (b) KEGG metabolic pathway based on the comparison of CE vs. NT that matches the chlorophyll metabolic pathway. KEGG nodes indicating upregulated genes are marked in red, KEGG nodes indicating downregulated genes are marked in green. Symbols: $\rightarrow$ synthesis, $-\rightarrow$ indirect synthesis, $\bigcirc$ synthesized product.

In our DEG analysis, we identified two genes, $\mathrm{ZjMgCH} 2$ and $\mathrm{ZjMgCH}$, encoding the magnesium $(\mathrm{Mg})$-chelatase enzyme functioning in $\mathrm{Mg}$ insertion into protoporphyrin IX (PIX). The Mg-chelatase acts at the branch point between the heme and Chl biosynthetic pathways [40]. Therefore, the enzyme is a crucial site for the regulation of the flow of tetrapyrrole intermediates through the $\mathrm{Chl}$ branch of this pathway from the common PIX intermediate [41]. Thus, the observed upregulation of $\mathrm{ZjMgCH} 2$ and $\mathrm{ZjMgCH} 3$ by ethephon pretreatment might have increased Chl synthesis, which eventually led to an elevated Chl content under cold stress.

ZjMPE cyclase encodes the Mg-protoporphyrin IX monomethyl ester (MPE) cyclase, which catalyzes the transformation of MPE into divinyl protochlorophyllide (DV-Pchlide). We found that ZjMPE cyclase was downregulated by ethephon pretreatment, which inhibited DV-Pchlide synthesis. The suppression of DV-Pchlide synthesis might indicate the slowdown of plant yellowing because previous research showed that DV-Pchlide is ubiquitous in the etiolated tissues of higher plants [42]. In addition, DV-Pchlide, along with other intermediates of the biosynthetic porphyrin pathway, tends to cause photo-oxidative damage in the chloroplasts after light absorption [43].

CAO encodes the Chla oxygenase, which catalyzes the Chlb formation by the oxygenation of Chla [44]. Ethephon pretreatment might have suppressed the conversion from Chla to Chlb under cold stress by downregulating ZjCAO. Therefore, the ethephon mediated an increase in the value of Chla/Chlb ratio, which is suggested to be an important determinant 
of maximum fluorescence intensity [45]. CLH encodes the chlorophyllase involved in Chl catabolism, catalyzing stress-induced Chl breakdown [46]. ZjCLH was upregulated under cold stress, whereas its expression level was not changed under cold stress with ethephon pretreatment. Therefore, ethephon pretreatment might have inhibited $\mathrm{Chl}$ degradation.

$\mathrm{PAO}$ and red $\mathrm{Chl}$ catabolite reductase (RCCR) are key enzymes involved in the PAOdependent $\mathrm{Chl}$ degradation pathway [47]. The removal of phytol and $\mathrm{Mg}$ from Chla generates pheophorbide a. ZjPAO and ZjRCCR catalyze the conversion of pheophorbide a to red Chl catabolite, which is used to produce primary fluorescent $\mathrm{Chl}$ catabolites [48]. In our study, cold stress decreased Chl content by increasing ZjPAO gene expression in $Z$. japonica plants. In contrast, ethephon pretreatment inhibited $\mathrm{Chl}$ catabolism under cold stress by downregulating the gene expression of $Z j P A O$ and ZjRCCR.

$S G R$ (Stay Green) is a regulator gene in Chl degradation [49]. RNA interference in the silencing of a homolog of the rice candidate gene in Arabidopsis demonstrated a stay-green phenotype [50]. Under cold stress, we found that ZjSGR was upregulated in Z. japonica plants, while it was downregulated by ethephon pretreatment. Thus, the downregulation of ZjSGR by ethephon pretreatment might have led to an elevated Chl content in Z. japonica under cold stress, but the underlying mechanism remains unknown. However, ethephon treatment might have suppressed ZjSGR transcription because ethylene is the key regulator for SGR transcription [51].

\subsection{Effect of Ethephon Application on Chl Content under Cold Stress}

$\mathrm{CE}$ plants maintained a higher $\mathrm{Chl}$ content and a higher $\mathrm{Chla/Chlb}$ ratio than control CS plants. The elevated Chl content could be caused by increased Chl synthesis and reduced $\mathrm{Chl}$ degradation. Ethephon treatment increased Chl synthesis by upregulating the $\mathrm{ZjMgCH} 2$ and $\mathrm{ZjMgCH} 3$ genes encoding Mg-catalase. Ethephon pretreatment diminished Chl degradation under cold stress by downregulating ZjPAO, ZjRCCR, and ZjSGR.

An elevated Chla/Chlb ratio could be due to a reduced conversion from Chla to $\mathrm{Chlb}$. The Chla/Chlb ratio, which is related to antenna size, is an indicator of functional pigment equipment and light adaptation [45]. The relatively high value of Chla/Chlb ratio is an index of stress adaptation due to a smaller light-harvesting complex, making PSII less susceptible during stress [52]. Thus, in our study, the downregulation of $Z j C A O$ by ethephon elevated Chla/Chlb ratio, which might have promoted the Z. japonica plants to adapt to stress.

\subsection{Gene Expression Analysis of Photosynthesis-Antenna Proteins}

Photosynthetic organisms use an array of light-harvesting antenna protein complexes to efficiently harvest solar energy [53]. The Lhca proteins are associated with the light-harvesting complexes of PSI, and the Lhcb proteins are associated with those of PSII $[54,55]$. The genes encoding the antennas of PSI and PSII are members of the light-harvesting complex $a(L h c a)$ and the light-harvesting complex $b(L h c b)$ multigene family, respectively [54]. The upregulation of ZjLhca1, ZjLhca3, and ZjLhca5 expression and downregulation of $Z j L h c b 6$ and $Z j L h c b 7$ expression indicate a coordinated PSI-stimulation and PSII-suppression strategy adapted in ethephon-pretreated plants under cold stress.

PSII catalyzes light-induced water oxidation in oxygenic photosynthesis to convert light into chemical energy [56,57]. However, PSII is the primary target of photoinhibition $[58,59]$. In higher plants, PSII is composed of two moieties: the core complex, which contains all the cofactors of the electron transport chain, and the outer antenna, which increases the light-harvesting capacity of the core [60]. In higher plants, the most abundant PSII-associated light-harvesting complex (LhcII) consists of homo- and heterotrimers of Lhcb1, Lhcb2, and Lhcb3 proteins [61]. The other Chla/b-binding proteins, Lhcb4, Lhcb5, and Lhcb6, also known as CP29, CP26, and CP24, exist as monomers [62-64]. ZjLhcb2 gene expression was upregulated in plants under cold stress, but its expression was not changed under cold stress with ethephon pretreatment. Furthermore, the expression of ZjLhcb6 and ZjLhcb7 was downregulated by ethephon pretreatment under cold stress. Lhcb2 and Lhcb6 
encode LhcII components [65], but Lhcb7 encodes a minor antenna protein associated with PSII [66]. Ethephon pretreatment downregulated genes encoding antenna proteins associated with PSII to minimize its light-harvesting capacity and diminish photoinhibition under cold stress.

PSI is the most efficient light energy converter in nature [67]. The efficiency of the complex is based on its capacity to deliver the energy quickly to the reaction center, which minimizes energy loss [68]. Lhca1 and Lhca2 very rapidly transfer energy to the PSI core, but these two complexes also transfer energy to Lhca3 and Lhca4 with a similar transfer rate. Although Lhca3 and Lhca4 also have a transfer energy directed to the core, their transfer rate is slow [68]. Here, we observed the upregulation of ZjLhca1 and ZjLhca3 by ethephon, which improved the capacity for energy delivery. Emilie et al. analyzed a PSI-LhcI complex that was identical to the WT complex, except for the substitution of Lhca4 with Lhca5; the comparison with the WT complex indicated that the energy transfer from Lhca5 to the core was faster than that from Lhca4 [69]. Thus, in our study, the upregulation of ZjLhca5 and the downregulation of ZjLhca4 might have increased the efficiency of energy delivery to the PSI core, but it only required a minor change in the photosynthetic apparatus.

The coordinated PSI-stimulation and PSII-suppression strategy mediated by ethephon can be further explained by the state transition theory. The state transition is a selfregulating mechanism in which photosynthetic apparatuses balance the excitation energy distribution between PSII and PSI and improve the efficiency of light energy utilization by reversibly changing the association of LhcII with PSII and PSI [70]. During State 1, LhcII is preferentially dephosphorylated and in association with PSII. During State 2, LhcII is partially phosphorylated and preferentially leaves PSII, resulting in an association with PSI [71,72]. When PSII absorbs excessive light, LhcII moves from PSII to PSI; then, the state transition occurs to equalize the electron transport between PSII and PSI, which increases the light absorption, fluorescence intensity, and activity of PSI [73,74]. In general, plants redistribute the light energy between PSI and PSII to improve the utilization for photosynthesis and prevent damage due to excessive light exposure [75]. In our study, ethephon pretreatment most likely promoted energy redistribution between PSI and PSII in Z. japonica under cold stress by regulating genes encoding antenna proteins.

Evidence showed that the absence of Chlb could change the orientation of pigment molecules, which could impair energy transfer [37]. In this study, a transcriptome analysis showed that spraying ethephon inhibited the synthesis of Chlb and redistributed the energy of PSI and PSII, which also confirmed the findings of previous studies.

\section{Materials and Methods}

\subsection{Plant Material and Growth Conditions}

Zoysia japonica Steud. cv. Chinese Common plants were obtained from the Turf Research Field of the Beijing Forestry University. After transplanting, the Z. japonica plants were randomly placed in the greenhouse of the Beijing Forestry University. The greenhouse conditions were as follows: light intensity of $400 \mu \mathrm{mol} \mathrm{m} \mathrm{m}^{-2} \mathrm{~s}^{-1}$, daily light period of $14 \mathrm{~h}$, day/night temperature regimen of $28 / 18^{\circ} \mathrm{C}$, and water $2-3$ times per week after transplanting. Fifteen pots of Z. japonica plants were transferred and acclimated in a growth chamber (day/night temperature of $28 / 18{ }^{\circ} \mathrm{C}$, light intensity of $3000 \mathrm{~lx}$, light period of $14 \mathrm{~h}$ ) for approximately one month. Plants were divided into three treatment groups (five pots per group): NT, normal day/night temperature regimen $\left(28 / 18^{\circ} \mathrm{C}\right)$ with water spray pretreatment as control; CS, cold stress $\left(4^{\circ} \mathrm{C}\right)$ with water spray pretreatment; and $\mathrm{CE}$, cold stress $\left(4^{\circ} \mathrm{C}\right)$ with ethephon spray pretreatment. Ethephon pretreatment was carried out on day 1 . Leaves were thoroughly sprayed with ethephon solution until liquid drops started to fall off. The concentration of ethephon was more than $150 \mathrm{mg} / \mathrm{L}$, which was determined by our team in a pervious study [29]. Starting on day 10, the CS and CE plants were subjected to cold stress for 18 days $\left(4^{\circ} \mathrm{C}\right.$ ) (Figure 7$)$. The cold treatment temperature was set according to Wei et al. [14]. At the end of treatment, fresh leaves of each group were collected. 


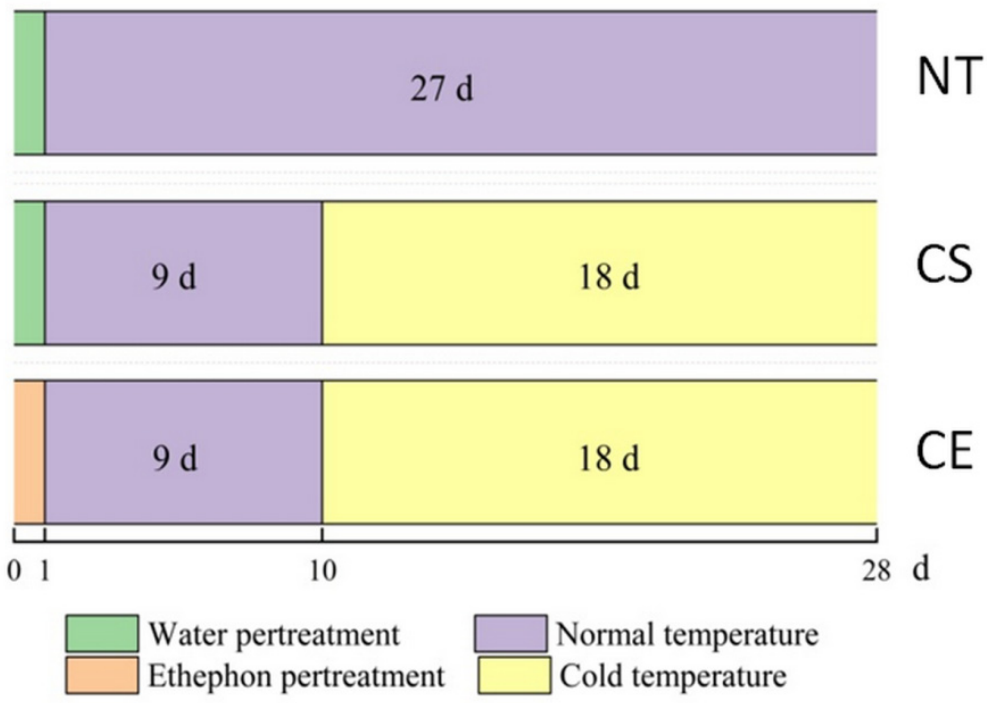

Figure 7. Treatment schedule for Z. japonica plants to test the effect of cold stress and ethephon treatment: NT (control), normal day/night temperatures $\left(28 / 18^{\circ} \mathrm{C}\right)$ with water spray pretreatment as control; CS, cold stress $\left(4^{\circ} \mathrm{C}\right)$ with water spray pretreatment; $\mathrm{CE}$, cold stress $\left(4^{\circ} \mathrm{C}\right)$ with ethephon spray pretreatment.

\subsection{Determination of Chl Content in Leaves}

Chl content was measured according to the method described previously [76]. Fresh leaves (approximately $0.05 \mathrm{~g}$ per sample) were cut into small sections of approximately $5 \mathrm{~mm}$ and placed into centrifuge tubes filled with $8 \mathrm{~mL}$ of $95 \%$ ethanol. Tubes were stored in the dark for $48 \mathrm{~h}$, and the absorption was measured at $665 \mathrm{~nm}, 649 \mathrm{~nm}$, and $470 \mathrm{~nm}$. The Chl content was calculated according to the following formula:

$$
\begin{aligned}
& \mathrm{Ca}=13.95 \mathrm{~A} 665-6.88 \mathrm{~A} 649, \mathrm{Cb}=24.96 \mathrm{~A} 649-7.32 \mathrm{~A} 665, \mathrm{CChl}=\mathrm{Ca}+\mathrm{Cb} \\
& \text { Chla content }=\mathrm{Ca} \times \frac{\mathrm{V}}{\mathrm{W}}, \text { Chlb content }=\mathrm{Cb} \times \frac{\mathrm{V}}{\mathrm{W}}, \mathrm{Chl} \text { content }=\mathrm{CChl} \times \frac{\mathrm{V}}{\mathrm{W}}
\end{aligned}
$$

In the formula, $\mathrm{C}_{\mathrm{a}}$ refers to the concentration of Chla $\left(\mathrm{mg} \mathrm{L}^{-1}\right), \mathrm{C}_{\mathrm{b}}$ to the concentration of Chlb (mg/L), $\mathrm{C}_{\mathrm{Chl}}$ to the total $\mathrm{Chl}$ concentration $\left(\mathrm{mg} \mathrm{L}^{-1}\right), \mathrm{V}$ to the volume after extraction (L), and $\mathrm{W}$ to the sample weight $(\mathrm{g})$.

We used a Chla/Chlb change percentage to calculate changes in Chla/Chlb ratio. Chla/Chlb change percentage were obtained by calculating the difference between the before-treatment (day 0) and after-treatment (day 28) values of each sample and dividing such a difference by before-treatment (day 0) and after-treatment (day 28). Chla/Chlb change percentage had positive and negative values, which indicated an increase or a decrease in Chla/Chlb after treatment, respectively:

$$
\frac{\text { Chla }}{\text { Chlb }} \text { ratio change percentage } \%=\frac{\text { day } 28-\text { day } 0}{\text { day } 0} \times 100 \%
$$

\subsection{Total RNA Extraction, RNA-Seq Library Construction, and RNA-Seq}

Total RNA was extracted from Z. japonica leaves according to the manufacturer's instructions of the TaKaRa MiniBEST Plant RNA Extraction Kit (Takara, Japan). A NanoPhotometer instrument was used to evaluate RNA purity $\left(\mathrm{OD}_{260 \mathrm{~nm}} / \mathrm{OD}_{280 \mathrm{~nm}}\right.$ and $\mathrm{OD}_{260 \mathrm{~nm}} / \mathrm{OD}_{230 \mathrm{~nm}}$ ratios), and an Agilent 2100 Bioanalyzer system was used to determined RNA integrity. The total RNA extracts were processed using magnetic beads with oligo(dT) primers to enrich the mRNA. The first cDNA strands were synthesized from short mRNA fragments, followed by the synthesis of the second strands. The new cDNA fragments were purified and subjected to end repair. The A bases were added to the $3^{\prime}$-ends, and the sequencing adapters were 
ligated to both ends of the cDNA fragments. The target size fragment fractions were recovered by agarose gel electrophoresis, and the PCR amplification was performed to complete the library preparation. Then, the effective library concentration was accurately quantified for library quality assurance. Illumina HiSeq ${ }^{\mathrm{TM}} 2500$ was used for second-generation sequencing after passing the library quality evaluation. We constructed a total of $9 \mathrm{cDNA}$ libraries of $Z$. japonica from the four treatment groups with three biological replicates each: NT (NT1, NT2, NT3), CS (CS1, CS2, CS3), and CE (CE1, CE2, CE3). The samples were submitted for sequencing by Illumina HiSeq ${ }^{\mathrm{TM}} 2500$ (Novogene Co., Ltd., Beijing, China) (http: / / www.novogene.com, accessed on 23 March 2019).

\subsection{RNA-Seq Data Processing and Assembly}

The original image data files obtained by Illumina $\mathrm{HiSeq}^{\mathrm{TM}}$ were converted into raw sequencing reads for analysis by CASAVA Base Calling [77]. Clean reads were obtained by filtering the original data and checking the sequencing error rate and GC content distribution. The clean reads were assembled based on sequence overlaps using the Trinity software [78]; the short sequence fragments were extended into longer fragments to obtain the fragment sets. The transcripts and unigene sequences were identified using the De Bruijin graph [79]. Clean reads were aligned with the reference genome of Z. japonica (http:/ / zoysia.kazusa.or.jp, accessed on 2 February 2022), and their locations were mapped with the TopHat2 algorithm [80]. The HTSeq software (Baltimore, MD, USA) and union model were used to analyze the gene expression levels of the samples. The Sequence Read Archive (SRA) data were submitted to NCBI (PRJNA741873).

\subsection{DEG Analysis}

Sequencing quality assessment and gene expression volume analysis were performed based on the sequences located on the genome. We estimated the gene expression levels with the most commonly used method based on the fragment counts per kilobase of gene transcript per one million reads (FPKM) [81]. DEGs were detected by comparing the data from different samples. DEGs were subsequently subjected to cluster analysis and evaluated using DESeq2. The DEGs were verified by correcting the threshold P-value of the DEGs using the Benjamini-Hochberg multiple testing procedure for calibration to obtain the false discovery rate (FDR/Padj). Fold change refers to the ratio of the relative expression levels between two samples, which is processed by the shrinkage model of difference analysis software, and finally takes the logarithm based on 2 samples. Padj $<0.05 \mid \log 2$ FoldChange $\mid>0$ are chosen as the screening criteria for DEGs with biological duplication [82]. DEG with $\log 2$ FoldChange value above 2 was considered to be significant.

\subsection{Annotation Analysis}

Gene Ontology (GO) is a comprehensive database describing gene function and can be divided into three parts: biological process, cellular component and molecular function. GO functional enrichment takes Padj $<0.05$ as the threshold of significant enrichment. The Kyoto Encyclopedia of Genes and Genomes (KEGG) is a comprehensive database that integrates information on the genome, chemistry, and system functions with data of the respective enzymes and genes [83]. KEGG pathway enrichment of DEGs was analyzed by clusterProfiler R software. A pathway satisfying the threshold Padj $<0.05$ was defined as a significantly enriched KEGG pathway for a DEG.

\section{7. qRT-PCR Confirmation}

Confirmation of RNA-Seq results by qRT-PCR was based on ten genes selected randomly from the comparison of CS vs. NT (Zjn_sc00026.1.g00600.1.am.mkhc, Zjn_sc00014.1.g01180.1.sm.mkhc, Zjn_sc00016.1.g04050.1.sm.mkhc, Zjn_sc00007.1.g00600.1.am.mkhc, Zjn_sc00086.1.g01640.1.am.mk) and CE vs. NT (Zjn_sc00133.1.g00260.1.am.mkhc, Zjn_sc00003.1.g01070.1.sm.mkhc, Zjn_sc00097.1.g01050.1.am.mk, Zjn_sc00017.1.g04240.1.sm.mkhc, Zjn_sc00016.1.g04940.1.am.mkhc). The cDNA preparations synthesized from the RNA samples were also used for qRT-PCR anal- 
ysis based on ten randomly selected genes. Three technical repeats were processed for each of the three biological repeats originally performed per treatment. The primers were designed and synthesized by RuiBiotech Co., Ltd. (http:/ / www.ruibiotech.com/, accessed on 2 February 2022) (Table 2). The instructions for the TB Green Premix Ex Taq kit (Tli RNaseH Plus) were obtained from Takara Bio Inc. (https:/ / www.takarabiomed.com.cn/, accessed on 2 February 2022), and the qRT-PCR was performed using a Bio Rad CFX Connect Real-Time PCR Detection System (Bio-Rad Laboratories Co., Ltd., California, USA) (https:/ / www.bio-rad.com/, accessed on 2 February 2022) with the following parameter settings: $95^{\circ} \mathrm{C}$ for $30 \mathrm{~s}$, followed by 40 cycles of $95^{\circ} \mathrm{C}$ for $5 \mathrm{~s}$ and annealing/extension at $60^{\circ} \mathrm{C}$ for $30 \mathrm{~s}$. Single-product amplification was confirmed with a melt curve.

Table 2. The target genes and primer sequences.

\begin{tabular}{|c|c|}
\hline Gene ID & Primer Sequence \\
\hline \multirow{2}{*}{ Actin } & F:5'-GGTGTTATGGTTGGGATGG-3' \\
\hline & R:5'-CAGTGAGCAGGACAGGGTG-3' \\
\hline \multirow{2}{*}{ Zjn_sc00026.1.g00600.1.am.mkhc } & F:5'-GCAGCAAGAACGAATGAT-3' \\
\hline & R:5'-CTGAAGAGTGGAAGGAGAA-3’ \\
\hline \multirow{2}{*}{ Zjn_sc00014.1.g01180.1.sm.mkhc } & F: GATGACAGAGATGCCAAT \\
\hline & R: CGATGAATACACCAGACA \\
\hline \multirow{2}{*}{ Zjn_sc00016.1.g04050.1.sm.mkhc } & F: GGCAAGTGGTATTAGTGAA \\
\hline & R: CAGTATGTGTTCCGTTGT \\
\hline \multirow{2}{*}{ Zjn_sc00007.1.g00600.1.am.mkhc } & F:GGACCTTGGACAGCATCTT \\
\hline & R:CGGCGACGAAGTAGAGAAT \\
\hline \multirow{2}{*}{ Zjn_sc00086.1.g01640.1.am.mk } & F:CACGGACCAAGGACTCAAG \\
\hline & R:CCAGCGTCAGTCACAAGA \\
\hline \multirow{2}{*}{ Zjn_sc00133.1.g00260.1.am.mkhc } & F:5'-GAAGGACACAGGAGTTGATG-3' \\
\hline & R:5'-CCATTACCAAGGCGTCTC-3' \\
\hline \multirow{2}{*}{ Zjn_sc00003.1.g01070.1.sm.mkhc } & F:5'-ATCСТTACACСАСТТССТ-3' \\
\hline & R:5'-CTCATCTCGCAACACATT-3' \\
\hline \multirow{2}{*}{ Zjn_sc00097.1.g01050.1.am.mk } & F:5'-CTACCACGCTCAATCCTAT-3' \\
\hline & R:5'-GTCATCCTCCTCTTCATCTT-3' \\
\hline \multirow{2}{*}{ Zjn_sc00017.1.g04240.1.sm.mkhc } & F: GGTGGTCATTGTGGATAA \\
\hline & R: GGAGTCAGGTTCAGATAAG \\
\hline \multirow{2}{*}{ Zjn_sc00016.1.g04940.1.am.mkhc } & F: GCAAGAATGGAACCTGTG \\
\hline & R: TCAGCAGCAATCTCATCA \\
\hline
\end{tabular}

\section{Conclusions}

Based on the transcriptome and chlorophyll content analysis, ethephon pretreatment increased the leaf chlorophyll content under cold stress by affecting two processes: the stimulation of chlorophyll synthesis by upregulating $\mathrm{ZjMgCH} 2$ and $\mathrm{ZjMgCH}$ expression and the suppression of chlorophyll degradation by downregulating ZjPAO, ZjRCCR, and ZjSGR expression. Furthermore, ethephon pretreatment increased the ratio of chlorophyll a to chlorophyll $\mathrm{b}$ in the leaves under cold stress, most likely by suppressing the conversion of chlorophyll a to chlorophyll $\mathrm{b}$ due to decreased chlorophyll b synthesis via the downregulation of ZjCAO. Additionally, the inhibition of chlorophyll b synthesis may result in an energy redistribution between photosystem II and photosystem I.

Supplementary Materials: The following supporting information can be downloaded at: https:/ / www.mdpi.com/article/10.3390/plants11030442/s1, Figure S1: Heat map of all differentially expressed genes in Z. japonica; Table S1: GO enrichment of CS vs. NT; Table S2: KEGG enrichment of CS vs. NT; Table S3: GO enrichment of CE vs. NT; Table S4: KEGG enrichment of CE vs. NT. Table S5: DEGs enriched in the KEGG pathway of porphyrin and chlorophyll metabolism; Table S6: DEGs enriched in the KEGG pathway of photosynthesis-antenna proteins.

Author Contributions: Methodology, W.L. and L.X.; formal analysis, J.Z. and W.L.; investigation, Z.Z., W.L. and L.L.; data curation, J.Z., Z.Z., W.L. and L.L.; writing-original draft preparation, J.Z. and W.L.; writing-review and editing, J.Z., L.H., L.X. and Y.Z.; supervision., L.H., L.X. and Y.Z.; 
formal analysis, J.Z. and W.L.; investigation, Z.Z., W.L. and L.L.; data curation, J.Z., Z.Z., W.L. and L.L.; writing —original draft preparation, J.Z. and W.L.; writing-review and editing, J.Z., L.H., L.X. and Y.Z.; supervision, L.H., L.X. and Y.Z. All authors have read and agreed to the published version of the manuscript.

Funding: This research was funded by "the Fundamental Research Funds for the Central Universities, grant number 2021ZY83" and "the National Natural Science Foundation of China, grant number 31860151".

Institutional Review Board Statement: Not applicable.

Informed Consent Statement: Not applicable.

Data Availability Statement: The data presented in this study are openly available in NCBI: reference number (PRJNA741873).

Conflicts of Interest: The authors declare no conflict of interest.

\section{References}

1. Chen, Y.; Zong, J.; Tan, Z.; Li, L.; Hu, B.; Chen, C.; Chen, J.; Liu, J. Systematic mining of salt-tolerant genes in halophyte-Zoysia matrella through cDNA expression library screening. Plant. Physiol. Biochem. 2015, 89, 44-52. [CrossRef]

2. Teng, K.; Tan, P.; Xiao, G.; Han, L.; Chang, Z.; Chao, Y. Heterologous expression of a novel Zoysia japonica salt-induced glycine-rich RNA-binding protein gene, ZjGRP, caused salt sensitivity in Arabidopsis. Plant. Cell Rep. 2017, 36, 179-191. [CrossRef]

3. Du, Y.; Yu, L.; Sun, J.; Lu, W.; Han, L. Study on Cold-resistance and Its Mechanism of Different Cultivars of Zoysia japonica Steud. Acta Agrestia Sin. 2008, 4, 347-352. [CrossRef]

4. Teng, K.; Chang, Z.; Li, X.; Sun, X.; Liang, X.; Xu, L.; Chao, Y.; Han, L. Functional and RNA-Sequencing Analysis Revealed Expression of a Novel Stay-Green Gene from Zoysia japonica (ZjSGR) Caused Chlorophyll Degradation and Accelerated Senescence in Arabidopsis. Front. Plant. Sci. 2016, 7, 1894-1907. [CrossRef]

5. Hu, W.; Wu, Y.; Zeng, J.; He, L.; Zeng, Q. Chill-induced inhibition of photosynthesis was alleviated by 24-epibrassinolide pretreatment in cucumber during chilling and subsequent recovery. Photosynthetica 2010, 48, 537-544. [CrossRef]

6. Palta, J.P.; Whitaker, B.D.; Weiss, L.S. Plasma membrane lipids associated with genetic variability in freezing tolerance and cold acclimation of solanum species. Plant. Physiol. 1993, 103, 793-803. [CrossRef]

7. Orvar, B.L.; Sangwan, V.; Omann, F.; Dhindsa, R.S. Early steps in cold sensing by plant cells: The role of actin cytoskeleton and membrane fluidity. Plant. J. 2000, 23, 785-794. [CrossRef]

8. Nobuhiro, S.; Ron, M. Reactive oxygen species and temperature stresses: A delicate balance between signaling and destruction Physiol. Plant. 2006, 126, 45-51. [CrossRef]

9. Hughes, M.A.; Dunn, M.A. The Effect of Temperature on Plant Growth and Development. Biotechnol. Genet. Eng. Rev. 2013, 8, 161-188. [CrossRef]

10. Mohabbati, F.; Paknejad, F.; Vazan, S.; Habibi, D.; Tookallo, M.R.; Moradi, F. Protective effect of exogenous PGPRs on chlorophyll florescence and membrane integrity of rice seedlings under chilling stress. Res. J. Appl. Sci. Eng. Technol. 2013, 5, 146-153. [CrossRef]

11. Zhang, X.; Wang, K.; Ervin, E.H.; Waltz, C.; Murphy, T. Metabolic changes during cold acclimation and deacclimation in five bermudagrass varieties. I. Proline, total amino acid, protein, and dehydrin expression. Crop. Sci. 2011, 51, 847-853. [CrossRef]

12. Ryoji, O.; Seiji, K. Reduction of chlorophyll fluorescence in zoysiagrasses at chilling and high temperatures with moderate light. Jpn. J. Grassl. Sci. 1995, 41, 31-36. [CrossRef]

13. Ryoji, O.; Seiji, K. Changes in photosynthetic oxygen evolution and chlorophyll fluorescence in some cool season grasses and zoysiagrasses (Zoysia spp.) from autumn to winter. Soil Sci. Plant. Nutr. 1995, 41, 801-806. [CrossRef]

14. Wei, S.; Du, Z.; Gao, F.; Ke, X.; Li, J.; Liu, J.; Zhou, Y. Global Transcriptome Profiles of 'Meyer' Zoysiagrass in Response to Cold Stress. PLoS ONE 2015, 10, e0131153. [CrossRef]

15. He, J.; Liu, H.; Wang, Y.; Guo, J. Low Temperature and Photosynthesis of Plants. Plant. Physiol. Commun. 1986, 2, 1-6. [CrossRef]

16. Ma, D.; Pang, J.; Huo, Z. Research Progress on low temperature tolerance of Cucumber. Tianjin Agric. Sci. 1997, 4, 3-10.

17. Nagata, N.; Tanaka, R.; Tanaka, A. The major route for chlorophyll synthesis includes [3,8-divinyl]-chlorophyllide a reduction in Arabidopsis thaliana. Plant. Cell Physiol. 2007, 48, 1803-1808. [CrossRef]

18. Zhao, Y.; Han, Q.; Ding, C.; Huang, Y.; Liao, J.; Chen, T.; Feng, S.; Zhou, L.; Zhang, Z.; Chen, Y.; et al. Effect of Low Temperature on Chlorophyll Biosynthesis and Chloroplast Biogenesis of Rice Seedlings during Greening. Int. J. Mol. Sci. 2020, 21, 1390. [CrossRef]

19. Pruzinská, A.; Tanner, G.; Anders, I.; Roca, M.; Hörtensteiner, S. Chlorophyll breakdown: Pheophorbide a oxygenase is a Rieske-type iron-sulfur protein, encoded by the accelerated cell death 1 gene. Proc. Natl. Acad. Sci. USA 2003, 100, 15259-15264. [CrossRef]

20. Tanimoto, M.; Roberts, K.; Dolan, L. Ethylene is a positive regulator of root hair development in emphArabidopsis thaliana. Plant. J. 1995, 8, 943-948. [CrossRef]

21. Lynch, J.; Brown, K.M. Ethylene and plant responses to nutritional stress. Physiol. Plant 1997, 100, 613-619. [CrossRef] 
22. Sharp, R.E.; LeNoble, M.E. ABA, ethylene and the control of shoot and root growth under water stress. J. Exp. Bot. 2002, 53, 33-37. [CrossRef]

23. Maruthasalam, S.; Ling, Y.S.; Murugan, L.; Wei, C.L.; Yi, L.L.; Ching, M.S.; Chih, W.Y.; Shu, H.H.; Yeong, K.; Chin, H.L. Forced flowering of pineapple (Ananas comosus cv. Tainon 17) in response to cold stress, ethephon and calcium carbide with or without activated charcoal. Plant Growth Regul. 2009, 60, 83-90. [CrossRef]

24. Han, L.; Han, L.; Xu, L. Effects of Ethephon Treatment on Plant Drought Tolerance. Acta Agrestia Sin. 2013, 21, 631-636. [CrossRef]

25. Wang, W.; Wang, Z.; Ping, J.; Zhang, Y. Effect of Ethephon on Several Cold Hardiness Indexes of Carbernet Sauvignon. Sino-Overseas Grapevine Wine 2005, 5, 14-15. [CrossRef]

26. Niu, H. Effects of DPCA, Paclobutrazol and ethephon on resistance of Larch Seedlings. Yunnan For. Sci. Technol. 1998, 3, 3-5. [CrossRef]

27. Wei, D.; Li, Y.; Di, N.; Bi, Z.; Bu, Z. Effect of Ethephon on Cold Resistance of Banana (Musa AAA Cavendish subgroup) Seedlings Chin. J. Trop. Crops 2009, 30, 1789-1792.

28. Sone, C.; Sakagami, J.I. Physiological mechanism of chlorophyll breakdown for leaves under complete submergence in rice. Crop. Sci. 2017, 57, 2729-2738. [CrossRef]

29. Liu, W. Application of Ethephon Impact Cold Tolerance of Zoysiagrass; Beijing Forestry University: Beijing, China, 2019.

30. Zhang, Z. Effects of Ethephon on Chlorophyll Metabolic Pathway of Zoysia Japonica under Low Temperature Stress; Beijing Forestry University: Beijing, China, 2020.

31. Wang, Z.; Gerstein, M.; Snyder, M. RNA-Seq: A revolutionary tool for transcriptomics. Nat. Rev. Genet. 2009, 10, 57-63. [CrossRef]

32. Wilhelm, B.T.; Landry, J.R. RNA-Seq-Quantitative measurement of expression through massively parallel RNA-sequencing. Methods 2009, 48, 249-257. [CrossRef]

33. Hu, X.; Makita, S.; Schelbert, S.; Sano, S.; Ochiai, M.; Tsuchiya, T.; Hasegawa, S.F.; Hörtensteiner, S.; Tanaka, A.; Tanaka, R. Reexamination of chlorophyllase function implies its involvement in defense against chewing herbivores. Plant. Physiol. 2015, 167, 660-670. [CrossRef] [PubMed]

34. Bushman, B.S.; Amundsen, K.L.; Warnke, S.E.; Robins, J.G.; Johnson, P.G. Transcriptome profiling of Kentucky bluegrass (Poa pratensis L.) accessions in response to salt stress. BMC Genom. 2016, 17, 48-59. [CrossRef] [PubMed]

35. Ma, Y.; Shukla, V.; Merewitz, E.B. Transcriptome analysis of creeping bentgrass exposed to drought stress and polyamine treatment. PLoS ONE 2017, 12, e175848. [CrossRef]

36. Wang, J.; An, C.; Guo, H.; Yang, X.; Chen, J.; Zong, J.; Li, J.; Liu, J. Physiological and transcriptomic analyses reveal the mechanisms underlying the salt tolerance of Zoysia japonica Steud. BMC Plant. Bio. 2020, 20, 114. [CrossRef]

37. Voitsekhovskaja, O.V.; Tyutereva, E.V. Chlorophyll b in angiosperms: Functions in photosynthesis, signaling and ontogenetic regulation. J. Plant. Physiol. 2015, 189, 51-64. [CrossRef]

38. Wang, G.; Chen, Z.; Zhang, Y.; Gong, G.; Wen, P. Effects of three plant growth substances on Chilling Resistance of potato. J. Huizhou Univ. 2018, 38, 21-28. [CrossRef]

39. Zhang, J.; Zhu, W. Effects of chilling stress on contents of chlorophyll and malondialdehyde in tomato seedlings. Acta Agric. Shanghai 2012, 28, 74-77.

40. Stenbaek, A.; Jensen, P.E. Redox Regulation of Chlorophyll Biosynthesis. Phytochemistry 2010, 71, 853-859. [CrossRef]

41. Pontier, D.; Albrieux, C.; Joyard, J.; Lagrange, T.; Block, M.A. Knock-out of the Magnesium Protoporphyrin IX Methyltransferase Gene in Arabidopsis: Effects on chloroplast development and on chloroplast-to-nucleus signaling. J. Biol. Chem. 2007, 282, 2297-2304. [CrossRef]

42. Shioi, Y.; Takamiya, K. Monovinyl and divinyl protochlorophyllide pools in etiolated tissues of higher plants. Plant Physiol. 1992, 100, 1291-1295. [CrossRef]

43. Reinbothe, S.; Reinbothe, C.; Apel, K.; Lebedev, N. Evolution of Chlorophyll Biosynthesis -The Challenge to Survive Photooxidation. Cell 1996, 86, 703-705. [CrossRef]

44. Tanaka, A.; Ito, H.; Tanaka, R.; Tanaka, N.K.; Yoshida, K.; Okada, K. Chlorophyll a oxygenase (CAO) is involved in chlorophyll b formation from chlorophyll a. Proc. Natl. Acad. Sci. USA 1998, 95, 12719-12723. [CrossRef]

45. Dinc, E.; Ceppi, M.G.; Toth, S.Z.; Bottka, S.; Schansker, G. The chla fluorescence intensity is remarkably insensitive to changes in the chlorophyll content of the leaf as long as the chla/b ratio remains unaffected. Biochim. Biophys. Acta 2012, 1817, 770-779. [CrossRef] [PubMed]

46. Hu, L.; Li, H.; Chen, L.; Lou, Y.; Amombo, E.; Fu, J. RNA-seq for gene identification and transcript profiling in relation to root growth of bermudagrass (Cynodon dactylon) under salinity stress. BMC Genom. 2015, 16, 575-586. [CrossRef]

47. Tang, Y.; Li, M.; Chen, Y.; Wu, P.; Wu, G.; Jiang, H. Knockdown of OsPAO and OsRCCR1 cause different plant death phenotypes in rice. J. Plant. Physiol. 2011, 168, 1952-1959. [CrossRef] [PubMed]

48. Liu, F.; Guo, F.Q. Nitric oxide deficiency accelerates chlorophyll breakdown and stability loss of thylakoid membranes during dark-induced leaf senescence in Arabidopsis. PLoS ONE 2013, 8, e56345. [CrossRef] [PubMed]

49. Park, S.Y.; Yu, J.W.; Park, J.S.; Li, J.; Yoo, S.C.; Lee, N.Y.; Lee, S.K.; Jeong, S.W.; Seo, H.S.; Koh, H.J.; et al. The senescence-induced staygreen protein regulates chlorophyll degradation. Plant Cell 2007, 19, 1649-1664. [CrossRef]

50. Armstead, I.; Donnison, I.; Aubry, S.; Harper, J.; Hörtensteiner, S.; James, C.; Mani, J.; Moffet, M.; Ougham, H.; Roberts, L.; et al. Cross-species identification of Mendel's I locus. Science 2007, 315, 73. [CrossRef] 
51. María, E.G.; Sofía, A.M.; Pedro, M.C.; Gustavo, A.M. Expression of Stay-Green encoding gene (BoSGR) during postharvest senescence of broccoli. Postharvest Biol. Technol. 2014, 95, 88-94. [CrossRef]

52. Caudle, K.L.; Johnson, L.C.; Baer, S.G.; Maricle, B.R. A comparison of seasonal foliar chlorophyll change among ecotypes and cultivars of Andropogon gerardii (Poaceae) by using nondestructive and destructive methods. Photosynthetica 2014, 52, 511-518. [CrossRef]

53. Damkjær, J.T.; Kereïche, S.; Johnson, M.P.; Kovacs, L.; Kiss, A.Z.; Boekema, E.J.; Ruban, A.V.; Horton, P.; Jansson, S. The photosystem II Light-Harvesting protein lhcb3 affects the macrostructure of photosystem II and the rate of state transitions in arabidopsis. Plant Cell 2009, 21, 3245-3256. [CrossRef] [PubMed]

54. Jansson, S. A guide to the Lhc genes and their relatives in Arabidopsis. Trends Plant. Sci. 1999, 4, 236-240. [CrossRef]

55. Klimmek, F.; Sjödin, A.; Noutsos, C.; Leister, D.; Jansson, S. Abundantly and rarely expressed Lhc protein genes exhibit distinct regulation patterns in plants. Plant. Physiol. 2006, 140, 793-804. [CrossRef]

56. Goussias, C.; Boussac, A.; Rutherford, A.W. Photosystem II and photosynthetic oxidation of water: An overview. Philos. Trans. R. Soc. B: Biol. Sci. 2002, 357, 1369-1381. [CrossRef] [PubMed]

57. Kawakami, K.; Shen, J.R. Purification of fully active and crystallizable photosystem II from thermophilic cyanobacteria. Methods Enzym. 2018, 613, 1-16. [CrossRef]

58. Barber, J.; Andersson, B. Too much of a good thing: Light can be bad for photosynthesis. Trends Biochem Sci. 1992, 17, 61-66. [CrossRef]

59. Chan, T.; Shimizu, Y.; Pospíšil, P.; Nijo, N.; Fujiwara, A.; Taninaka, Y.; Ishikawa, T.; Hori, H.; Nanba, D.; Imai, A.; et al. Quality control of photosystem II: Lipid peroxidation accelerates photoinhibition under excessive illumination. PLoS ONE 2012, 7, e52100. [CrossRef]

60. Dekker, J.P.; Boekema, E.J. Supramolecular organization of thylakoid membrane proteins in green plants. Biochim. Biophys. Acta 2005, 1706, 12-39. [CrossRef]

61. Drop, B.; Webber-Birungi, M.; Yadav, S.K.; Filipowicz-Szymanska, A.; Fusetti, F.; Boekema, E.J.; Croce, R. Light-harvesting complex II (LHCII) and its supramolecular organization in Chlamydomonas reinhardtii. Biochim. Biophys. Acta 2014, 1837, 63-72. [CrossRef]

62. Croce, R.; Canino, G.; Ros, F.; Bassi, R. Chromophore organization in the higher-plant photosystem II antenna protein CP26. Biochem 2002, 41, 7334-7343. [CrossRef]

63. Passarini, F.; Wientjes, E.; Hienerwadel, R.; Croce, R. Molecular basis of light harvesting and photoprotection in CP24: Unique features of the most recent antenna complex. J. Biol. Chem. 2009, 284, 29536-29546. [CrossRef] [PubMed]

64. Pan, X.; Li, M.; Wan, T.; Wang, L.; Jia, C.; Hou, Z.; Zhao, X.; Zhang, J.; Chang, W. Structural insights into energy regulation of light-harvesting complex CP29 from spinach. Nat. Struct. Mol. Biol. 2011, 18, 309-315. [CrossRef] [PubMed]

65. Peng, X.; Deng, X.; Tang, X.; Tan, T.; Zhang, D.; Liu, B.; Lin, H. Involvement of Lhcb6 and Lhcb5 in Photosynthesis Regulation in Physcomitrella patens Response to Abiotic Stress. Int. J. Mol. Sci. 2019, 20, 3665. [CrossRef] [PubMed]

66. Peers, G.; Niyogi, K.K. Pond scum genomics: The genomes of chlamydomonas and ostreococcus. Plant Cell 2008, $20,502-507$. [CrossRef]

67. Nelson, N. Plant photosystem I-the most efficient Nano-Photochemical machine. J. Nanosci. Nanotechnol. 2009, 9, 1709-1713. [CrossRef]

68. Croce, R.; van Amerongen, H. Light-harvesting in photosystem I. Photosynth Res. 2013, 116, 153-166. [CrossRef]

69. Wientjes, E.; van Stokkum, I.H.; van Amerongen, H.; Croce, R. The role of the individual Lhcas in photosystem I excitation energy trapping. Biophys. J. 2011, 101, 745-754. [CrossRef]

70. Bellafiore, S.; Barneche, F.; Peltier, G.; Rochaix, J. State transitions and light adaptation require chloroplast thylakoid protein kinase STN7. Nature 2005, 433, 892-895. [CrossRef]

71. Allen, J.F. BOTANY: State transitions-a question of balance. Science 2003, 299, 1530-1532. [CrossRef]

72. Kanervo, E.; Suorsa, M.; Aro, E.M. Functional flexibility and acclimation of the thylakoid membrane. Photochem. Photobiol. Sci. 2005, 4, 1072-1080. [CrossRef]

73. Haldrup, A.; Jensen, P.E.; Lunde, C.; Scheller, H.V. Balance of power: A view of the mechanism of photosynthetic state transitions. Trends Plant. Sci. 2001, 6, 301-305. [CrossRef]

74. Nawrocki, W.J.; Santabarbara, S.; Mosebach, L.; Wollman, F.A.; Rappaport, F. State transitions redistribute rather than dissipate energy between the two photosystems in Chlamydomonas. Nature Plants. 2016, 2, 16031. [CrossRef] [PubMed]

75. Allen, J.F. Protein phosphorylation in regulation of photosynthesis. Biochim. Biophys. Acta 1992, 1098, 275-335. [CrossRef]

76. Sartory, D.P.; Grobbelaar, J.U. Extraction of chlorophyll a from freshwater phytoplankton for spectrophotometric analysis. Hydrobiologia 1984, 114, 177-187. [CrossRef]

77. Chi, Y.; Ren, T.; Shi, X.; Jin, X.; Jin, P. Mechanism of nutrient removal enhancement in low carbon/nitrogen wastewater by a novel high-frequency micro-aeration/anoxic (HMOA) mode. Chemosphere 2021, 263, 128003. [CrossRef] [PubMed]

78. Li, B.; Dewey, C.N. RSEM: Accurate transcript quantification from RNA-Seq data with or without a reference genome. BMC Bioinform. 2011, 12, 323-338. [CrossRef]

79. Grabherr, M.G.; Haas, B.J.; Yassour, M.; Levin, J.Z.; Thompson, D.A.; Amit, I.; Adiconis, X.; Fan, L.; Raychowdhury, R.; Zeng, Q.; et al. Full-length transcriptome assembly from RNA-Seq data without a reference genome. Nat. Biotechnol. 2011, 29, 644-652. [CrossRef] 
80. Kim, D.; Pertea, G.; Trapnell, C.; Pimentel, H.; Kelley, R.; Salzberg, S.L. TopHat2: Accurate alignment of transcriptomes in the presence of insertions, deletions and gene fusions. Genome Biol. 2013, 14, R36. [CrossRef]

81. Mortazavi, A.; Williams, B.A.; McCue, K.; Schaeffer, L.; Wold, B. Mapping and quantifying mammalian transcriptomes by RNA-Seq. Nat. Methods 2008, 5, 621-628. [CrossRef]

82. Love, M.I.; Huber, W.; Anders, S. Moderated estimation of fold change and dispersion for RNA-seq data with DESeq2. Genome Biol. 2014, 15, 550-570. [CrossRef]

83. Hadadi, N.; MohammadiPeyhani, H.; Miskovic, L.; Seijo, M.; Hatzimanikatis, V. Enzyme annotation for orphan and novel reactions using knowledge of substrate reactive sites. Proc. Natl. Acad. Sci. USA 2019, 116, 7298-7307. [CrossRef] 